Jurnal Ekonomi, Bisnis, dan Akuntansi (JEBA) Volume 21 Nomor 01 Tahun 2019

\title{
PENGARUH KEPEMIMPINAN, KETERLIBATAN KARYAWAN DAN KEPUASAN KERJA TERHADAP KESIAPAN UNTUK BERUBAH DALAM MENGHADAPI PERUBAHAN ORGANISASI
}

\author{
Hendro Susyanto \\ Magister Manajemen, Fakultas Ekonomi dan Bisnis, Universitas Jenderal Soedirman \\ Email Corresponding Author : hendro.susyanto1982@gmail.com
}

\begin{abstract}
In the tight competition for cement sales in Indonesia's market share and also excessive cement supply compared to demand, the management of PT Holcim Indonesia made organizational changes to increase the level of competency for increasingly large competitors both domestically and abroad. Changes have been made include the replacement of top management (CEO and BOD), changes in the company's vision and mission as well as the reduction of employees during 2014-2016. This has an impact on the company's performance, especially the operations of Cilacap plant which has decreased performance during the organizational change process. Various organizational development policies have been carried out by management to improve employees' readiness to change and if we are looking for factory operating parameters, there is an increase in performance after the fourth year (2017). The Objective of this research is to determine the level of readiness of employees to change which is influenced by leadership factors (transformational and transactional), employee involvement, level of job satisfaction in the PT Holcim Tbk plant Cilacap. The result of this research indicates that employees of PT Holcim Indonesia Cilacap factory have a high readiness to change and this is positively influenced by employee involvement and job satisfaction, while leadership factors do not directly influence readiness to change but through intervening variables namely job satisfaction and employee involvement.
\end{abstract}

Keywords: Readiness to Change, Transformational, Transactional, Employee Involvement, Job Satisfaction

\begin{abstract}
Abstrak
Di dalam persaingan penjualan semen di pangsa pasar Indonesia yang semakin ketat dan kelebihan pasokan semen dibandingkan permintaan, manajemen PT Holcim Indonesia melakukan perubahan organisasi untuk meningkatkan tingkat kompetensi terhadap para competitor yang semakin banyak baik dari dalam negeri maupun luar negeri. Perubahan yang dilakukan diantaranya penggantian manajemen puncak (CEO dan BOD), perubahan visi dan misi perusahaan serta pengurangan karyawan pada tahun 2014 - 2016. Hal ini berdampak pada kinerja perusahaan khususnya operasional pabrik Cilacap yang mengalami penurunan kinerja selama proses perubahan organisasi tersebut. Berbagai kebijakan pengembangan organisasi telah dilakukan oleh manajemen untuk meningkatkan kesiapan karyawan untuk berubah dan jika mengacu pada parameter operasi pabrik, terjadi peningkatan kinerja setelah tahun ke empat (2017). Tujuan penelitian ini adalah untuk mengetahui tingkat kesiapan karyawan untuk berubah yang dipengaruhi oleh faktor kepemimpinan (transformasional dan transaksional), keterlibatan karyawan, tingkat kepuasan kerja di lingkungan PT Holcim Tbk pabrik cilacap. Hasil penelitian ini menunjukan bahwa karyawan PT Holcim Indonesia pabrik Cilacap memiliki kesiapan untuk berubah yang tinggi dan hal tersebut dipengaruhi secar positif oleh keterlibatan karyawan dan kepuasan kerja, sedangkan faktor kepemimpinan tidak berpengaruh langsung terhadap kesiapan untuk berubah tetapi melalui variable intervening yaitu kepuasan kerja dan keterlibatan karyawan.
\end{abstract}

Kata Kunci: Kesiapan untuk Berubah, Transformasional, Transaksional, Keterlibatan Karyawan, Kepuasan Kerja 


\section{PENDAHULUAN}

Pada era persaingan global saat ini, laju perubahan yang memengaruhi bisnis semakin meningkat. Banyak perubahan baru dan inisiatif transformasional telah dikembangkan untuk meningkatkan kinerja organisasi dan mencapai keunggulan kompetitif yang berkelanjutan (Wanberg dan Banas, 2000; By, 2007; Shah, 2011; Fuentes-Henrıquez dan Del Sol, 2012). Literatur penelitian di bidang manajemen perubahan telah menetapkan bahwa Kesiapan Individu untuk Berubah (individual Readiness for change/ IRFC) adalah salah satu faktor paling signifikan terhadap keberhasilan implementasi perubahan organisasi (Armenakis et al., 1993; Weeks et al., 1995; Clegg dan Walsh, 2004; Jones et al., 2005; Holt et al., 2007; Sikh, 2011). Menurut para peneliti, mengabaikan peran vital individu dalam proses perubahan, menyebabkan kegagalan atau kesulitan dalam melaksanakan banyak inisiatif perubahan (Armenakis et al., 1993; Weeks et al., 1995; Clegg dan Walsh, 2004; Jones et al., 2005; Holt et al., 2007; Sikh, 2011). Kegagalan program perubahan untuk mencapai hasil yang diinginkan sering kali dikaitkan dengan resistensi karyawan terhadap perubahan (Bovey dan Hede, 2001), sementara banyak peneliti lain yang mengakui bahwa sikap karyawan yang positif terhadap perubahan sangat penting untuk mencapai tujuan organisasi (Eby et al., 2000; Weber dan Weber, 2000).

Di tengah kondisi pasar yang dinamis dan tidak seimbangnya antara pasokan yang berlebih terhadap permintaan, total penjualan PT Holcim Indonesia Tbk mengalami penurunan dibandingkan tahun - tahun sebelumnya. Merespon kondisi tersebut, PT. Holcim Indonesia Tbk melakukan berbagai program perubahan organisasi dimulai dengan pergantian kepemimpinan di level manajemen puncak serta perubahan visi dan misi perusahaan. Berbagai kebijakan pengembangan organisasi telah dilakukan untuk meningkatkan daya saing perusahaan di pangsa pasar penjualan semen. Perubahan organisasi ini harus disikapi dengan baik oleh manajemen agar kinerja perusahaan tetap positif dan berkelanjutan di masa mendatang. Salah satu sikap atau persepsi yang dapat memengaruhi kegiatan perubahan organisasi adalah kesiapan organisasi untuk berubah. Kesiapan organisasi dapat didefinisikan sebagai persepsi anggota organisasi, keyakinan, sikap dan harapan sejauh mana organisasi siap dan mampu memperkenalkan serta menerapkan perubahan dalam rangka meningkatkan kinerja (Armenakis et al., 1993; Pond et al., 1984; Weber dan Weber, 2000). Kesiapan organisasi untuk berubah mirip dengan konsep "unfreezing" Lewin (Armenakis et al., 1993; Eby et al., 2000), yang merupakan "proses di mana keyakinan dan sikap anggota organisasi tentang perubahan yang tertunda diubah sehingga anggota mempersepsikan perubahan itu karena diperlukan dan sangat mungkin berhasil" (Armenakis, et al., 1993, p.422).

Salah satu faktor yang mendukung kesiapan untuk berubah dalam keberhasilan suatu perubahan organisasi diantaranya adalah keterlibatan karyawan. Keterlibatan karyawan adalah proses partisipatif yang menggunakan masukan karyawan untuk meningkatkan komitmen mereka terhadap kesuksesan organisasi. Selain keterlibatan kerja, faktor lain yang memengaruhi kesiapan karyawan untuk perubahan adalah komitmen manajer senior untuk perubahan, kemampuan agen perubahan dan dukungan dari manajer langsung (Cinite et al., 2009). Kemampuan pemimpin untuk memotivasi, berkomunikasi dan membangun suatu tim menjadi predictor yang kuat untuk menerapkan perubahan yang sukses (Gilley et al., 2009). Selain itu, kemampuan pemimpin yang memiliki pengaruh kuat dan positif pada kecenderungan inovasi (Ryan dan Tipu, 2013) dapat memengaruhi proses 
inisiasi perubahan (Talim, 2012). Gaya kepemimpinan yang berbeda akan direspon yang berbeda pula oleh bawahan dan akan berdampak pada kinerja individu dan pencapaian tim. Tingkat kepuasan kerja juga dapat memengaruhi kesiapan karyawan untuk berubah pada saat terjadi perubahan organisasi. Karyawan dengan tingkat kepuasan kerja yang tinggi akan lebih siap menerima perubahan. Di dalam penelitian Al Hussami (2014), manajer perawat dengan kepuasan lebih pada pekerjaan dilaporkan memiliki kesiapan untuk perubahan yang lebih tinggi. Temuan yang sama ditemukan juga di pelatihan umum staf keperawatan di Australia (Christl et al., 2010). Demikian pula, korelasi tinggi ditemukan antara kepuasan dengan kepemimpinan dan kesiapan yang dirasakan untuk perubahan di penyedia perawatan kesehatan yang bekerja baik di pusat medis maupun departemen rawat jalan di Amerika Serikat (Helfrich et al., 2011). Penelitian ini akan menguji secara empiris mengenai kesiapan untuk berubah yang dipengaruhi oleh faktor kepemimpinan, keterlibatan karyawan dan tingkat kepuasan kerja karyawan di dalam lingkungan PT Holcim Indonesia Tbk Pabrik Cilacap khususnya pada bagian unit bisnis yang berhubungan dengan operasional pabrik yaitu divisi produksi, pemeliharaan, teknikal dan supporting.

\section{TINJAUAN PUSTAKA DAN PERUMUSAN HIPOTESIS}

\section{Kesiapan untuk Berubah}

Kesiapan untuk berubah didefinisikan sebagai sikap komperehensif yang secara stimultan dipengaruhi oleh isi, proses, konteks dan individu yang terlibat dalam suatu perubahan, merefleksikan sejauh mana kecenderungan individu untuk menyetujui, menerima dan mengadopsi rencana spesifik yang bertujuan untuk mengubah keadaan saat ini (Holt, 2007). Business Harvard Review mendeskripsikan kesiapan untuk berubah sebagai kemampuan untuk terus berinisiatif dan menanggapi perubahan dengan cara yang menciptakan keuntungan, meminimalkan risiko, dan mempertahankan kinerja. Menurut Holt (2007), kesiapan untuk berubah adalah suatu hal yang perlu ditinjau sebelum melakukan perubahan organisasi. Kesiapan adalah kepercayaan karyawan bahwa mereka mampu melaksanakan perubahan yang diusulkan, perubahan yang diusulkan tepat untuk dilakukan oleh organisasi, pemimpin berkomitmen dalam perubahan yang diusulkan, dan perubahan yang diusulkan akan memberikan keuntungan bagi anggota organisasi. Dari pernyataan tersebut kesiapan untuk berubah akan menunjukkan perilaku menerima, merangkul, dan mengadopsi rencana perubahan yang dilakukan. Banyak penulis telah mulai menekankan konsep kesiapan individu untuk perubahan (Jones et al., 2005; Holt et al., 2007; Choi dan Ruona, 2011). Sejumlah akademisi seperti Armenakis et al (1993), Clegg dan Walsh (2004), Jones et al (2005) dan Holt et al (2007) telah menyoroti pentingnya faktor psikologis atau faktor manusia dalam upaya implementasi perubahan. Menurut para peneliti, mengabaikan peran vital individu dalam proses perubahan, menyebabkan kegagalan atau kesulitan dalam melaksanakan banyak inisiatif perubahan (Armenakis et al., 1993; Weeks et al., 1995; Clegg dan Walsh, 2004; Jones et al ., 2005; Holt et al., 2007; Sikh, 2011).

\section{Kepemimpinan}

Kepemimpinan adalah kemampuan untuk memengaruhi tim untuk mencapai tujuan. Bass (1998) mendefinisikan kepemimpinan adalah penuh perhatian kepada orang-orang dalam hal menyediakan kepada bawahan berupa dukungan, mentoring dan coaching. Kepemimpinan adalah proses dimana seseorang memengaruhi suatu kelompok yang terdiri dari individu-individu untuk mencapai tujuan (Northouse, 2013). Pemikiran terkini tentang 
efektivitas kepemimpinan telah di lakukan dengan pendekatan situasi yang menekankan pada kepemimpinan karisma, kemampuan mengembangkan dan mengimplementasikan visi di organisası dan kemampuan mengajarkan pekerja untuk bertindak sebagai self-leader. Kepemimpinan tersebut dikembangkan oleh Bass (1998) yaitu transaksional dan transformasional. Bass (1998) menjelaskan bahwa kepemimpinan transaksional menekankan transaksi atau pertukaran sesuatu antara leader, rekan dan pengikutnya dimana pertukaran tersebut didasarkan pada diskusi dengan leader tentang apa yang disyaratkan dan menyebutkan kondisi khusus serta memberikan penghargaan. Kepemimpinan ini terjadi jika leader memberikan penghargaan kepada bawahan yang tergantung pada bentuk yang dilakukan yaitu contigency reward, management by exception active (MBE-A) dan management by exception passive (MBE-P).

Implementasi tipe kepemimpinan di organisasi tergantung situasi, Bass (1998) menyampaikan bahwa kepemimpinan transaksional adalah cukup efektif ketika pemimpin menemui kondisi yang stabil dan lingkungan yang bisa ditebak, sedangkan kepemimpinan transformasional muncul di dalam organisasi dan menjadi efektif jika dalam kondisi yang tidak stabil, tidak menentu dan lingkungan yang banyak kejadian, banyak perubahan secara cepat dan ketidak adanya pandangan ke depan. Tentunya situasi tersebut harus ditentukan sendiri oleh seorang pemimpin agar dia bisa mencapai kinerja yang baik dengan cepat, tepat dan efisien, namun tetap memiliki hubungan yang baik dengan anak buahnya. Mendapatkan dukungan dari anak buah adalah penting dalam menyukseskan visi yang akan dicapai, karena hubungan yang tidak baik akan berdampak pada dukungan dari anak buah dalam mencapai tujuan organisasi menjadi terhambat yang dapat menyebabkan kegagalan dalam pencapaian tujuan atau terlambatnya pencapaian tujuan.

\section{Keterlibatan Karyawan}

Teori Keterlibatan karyawan menekankan pada pendelegasian kekuasaan, informasi, penghargaan dan pelatihan ke tingkat terendah yang memungkinkan dalam hierarki organisasi untuk meningkatkan kebebasan bertindak bagi karyawan (Cotton,1993; Lawler,1994). Richardson menggunakan hierarki berdasarkan tiga tingkat keterlibatan. Tingkat pertama tercapai ketika manajemen membuat upaya untuk meningkatkan komunikasi dan sikap, tetapi masih memandang karyawan sebagai relasi pasif. Tingkat kedua tercapai ketika manajemen bekerja secara aktif untuk melibatkan karyawan dalam peningkatan produktivitas dan manajemen biaya. Pada tingkat ketiga, manajemen memandang karyawan sebagai mitra dalam perusahaan dan memberi imbalan kepada upaya melalui pembagian keuntungan atau skema pembagian laba.

Dalam kerangka kerja Lawler tentang manajemen keterlibatan tinggi, ada tiga sumber daya organisasi lainnya yang perlu dide-sentralisasikan agar karyawan memiliki kapasitas untuk menciptakan organisasi berkinerja tinggi yaitu Pengetahuan, yang memungkinkan karyawan untuk memahami dan berkontribusi terhadap kinerja organisasi. Informasi tentang kinerja organisasi, Informasi tersebut termasuk data yang terkait dengan produksi (pendapatan, biaya, penjualan, laba, struktur biaya), kepuasan pelanggan dan tolok ukur dengan perusahaan lain. Penghargaan untuk kinerja tinggi termasuk menyesuaikan struktur kompensasi agar selaras dengan perilaku, hasil, dan kemampuan yang diperlukan untuk kinerja tinggi. Karyawan dapat dibayar berdasarkan pengetahuan dan keterampilan yang dibutuhkan di lingkungan kerja untuk menyelesaikan pekerjaan. York (1995) berpendapat bahwa keterlibatan sejati adalah menarik orang yang lebih rendah hirarkinya ke tingkat di atas mereka dan kemudian berbagi kekuatan yang ada. 


\section{Kepuasan Kerja}

Robbins dan Judge (2013) mendefinisikan kepuasan kerja adalah perasaan positif tentang pekerjaan yang dihasilkan dari evaluasi dengan karakteristik yang jelas dan luas. Pekerjaan memerlukan interaksi dengan rekan kerja dan atasan, mengikuti aturan dan kebijakan organisasi, memenuhi standar kinerja, hidup dengan kondisi kerja yang kurang dari ideal, dan sejenisnya. Locke (1976) dalam Biswas (2012) mendefiniskan kepuasan kerja sebagai keadaan emosional yang menyenangkan atau positif yang dihasilkan dari penilaian pekerjaan atau pengalaman kerja. Orang akan dipuaskan dengan pekerjaannya selama mereka menerima persepsi bahwa pekerjaan mereka sesuai dengan nilai-nilai penting mereka seperti sifat seseorang, peran dan tugas di dalam pekerjaan, atasan mereka, rekan kerja dan gaji serta manfaat yang diterima. Perasaan senang dan gembira dalam menjalankan suatu pekerjaan adalah bagian yang menyebabkan seseorang puas terhadap pekerjaan. Seseorang juga bisa merasakan puas karena telah menyelesaikan pekerjaan yang menantang dimana tidak semua orang bisa menyelesaikan pekerjaan tersebut di lihat dari tingkat kesulitan, kompleksitas pekerjaan dan waktu yang diberikan. Kepuasan ini akan menjaga dan meningkatkan motivasi mereka dalam menjalankan tugas dan pekerjaan mereka, sehingga kinerja mereka akan tercapai bahkan mampu mengerjakan tugas tugas lain yang di luar tanggung jawabnya.

Robbins dan Judge (2013) menyampaikan bahwa penelitian menunjukkan tingkat kepuasan yang bervariasi yaitu orang lebih puas dengan pekerjaan mereka secara keseluruhan, pekerjaan itu sendiri, dengan supervisor dan rekan kerja daripada dengan gaji mereka dan dengan peluang promosi bagi mereka. Levi (2002) menyampaikan lima komponen yang terdapat dalam kepuasan kerja, yaitu Pekerjaan itu sendiri, Atasan, Teman Sekerja, Promosi, dan Gaji/Upah.

\section{Perumusan Hipotesis}

Bommer et al (2005) menemukan pemimpin dengan gaya kepemimpinan transformasional sangat efektif untuk menerapkan perubahan dalam organisasi mereka. Para pemimpin itu adalah pemikir karismatik, visioner, berani mengambil risiko, energetik dan out-of-the-box serta memiliki kemampuan untuk memotivasi orang lain ketika bertindak sebagai model peran dan mentor bagi pengikut mereka (Ward, 2002). Secara bersamaan, manajer yang menggunakan kepemimpinan transformasional memiliki kepuasan kerja yang baik dan lebih berkomitmen untuk organisasi mereka (Emery dan Barker, 2007; Munir et al., 2012; Schwartz et al., 2011), dan gaya mereka sangat terkait dengan persepsi konflik pekerjaan hidup dan kesejahteraan psikologis (Munir et al., 2012). Pemimpin dengan karakteristik transformasional dapat mengatasi lingkungan kerja yang kompleks dan berubah dengan cepat (Murphy, 2005), merupakan agen perubahan positif (Ward, 2002), memiliki sikap positif untuk menerapkan praktik berbasis bukti (Aarons, 2006) dan memengaruhi budaya organisasi secara positif (Shiva dan Suar, 2012). Van der Voet (2014) menemukan bahwa para pemimpin tersebut hanya berkontribusi sedikit terhadap perubahan organisasi yang direncanakan dan Nordin (2011) menemukan bahwa gaya kepemimpinan transaksional lebih dapat memprediksi kesiapan organisasi untuk perubahan. Dari penjabaran literatur di atas, maka penulis membuat hipotesis sebagai berikut:

\section{H1: Kepemimpinan transformasional berpengaruh positif terhadap kesiapan karyawan untuk berubah}




\section{H2: Kepemimpinan transaksional berpengaruh positif terhadap kesiapan karyawan untuk berubah}

Sejumlah akademisi seperti Armenakis et al (1993), Clegg dan Walsh (2004), Jones et al (2005) dan Holt et al (2007) menyoroti pentingnya faktor psikologis atau faktor manusia dalam upaya implementasi perubahan. Umumnya peneliti yang fokus pada kesiapan karyawan memprediksi bahwa peran agen perubahan, proses yang tepat, partisipasi, keyakinan, lingkungan, keadilan dan komitmen terkait dengan kesiapan karyawan (Hanpachern et al., 1998; Eby et al., 2000; Cunningham et al., 2002; Madsen et al., 2005; Rafferty dan Simons, 2006; Bernerth et al., 2007). Keterlibatan karyawan dalam perubahan dapat mengurangi resistensi karena memahami kebutuhan untuk perubahan dan kemampuan yang dirasakan untuk berubah sangat lah penting (Armenakis et al., 1993; Wanberg dan Banas, 2000). Dari penjabaran literatur di atas, maka penulis membuat hipotesis sebagai berikut:

\section{H3: Tingkat keterlibatan karyawan berpengaruh positif terhadap kesiapan individu untuk berubah}

Bass (1998) menyampaikan bahwa banyak studi penelitian menunjukkan bahwa kepemimpinan transformasional lebih memuaskan dibanding dengan kepemimpinan transaksional. Penelitian tersebut merupakan hasil penelitian yang dilakukan oleh Gaspar (1992) kemudian dikuatkan oleh Patterson, Fuller dan Stringer (1995). Sehingga bisa dikatakan bahwa kepemimpinan transformasional dan transaksional berpengaruh terhadap kepuasan kerja walaupun derajat kepuasannya berbeda diantara keduanya. Hasil penelitian Saros dan Santora (2001) menunjukkan bahwa kinerja kepemimpinan transformasional memiliki nilai efektif dibandingkan dengan kepemimpinan transaksional. Dari penjabaran literatur di atas, maka penulis membuat hipotesis sebagai berikut:

\section{H4: Kepemimpinan transformasional berpengaruh positif terhadap kepuasan kerja \\ H5: Kepemimpinan transaksional berpengaruh positif terhadap kepuasan kerja}

Locke dan Schweiger (1979) dalam Dow Scott et al (2003) mendefinisikan partisipasi pembuatan keputusan sebagai keterlibatan dalam proses mencapai keputusan. Wall et al (1986) menghubungkan keterlibatan karyawan dengan kepuasan kerja. Zatzick dan Iverson (2012) dalam penelitiannya menghasilkan bahwa ada hubungan positif antara keterlibatan karyawan terhadap kepuasan kerja, dan juga penelitian oleh KF PUN et al (2001) menghasilkan bahwa ada hubungan positif antara keterlibatan karyawan terhadap kepuasan kerja. Zatzick dan Iverson (2011) menyampaikan bahwa konsep keterlibatan karyawan biasanya diterapkan pada tingkat karyawan yang lebih rendah dan berfokus pada peluang mereka untuk membuat keputusan tentang pekerjaan mereka, serta partisipasi mereka dalam seluruh kegiatan bisnis. Melibatkan karyawan untuk berpartisipasi dalam keputusan yang berhubungan dengan pekerjaan adalah salah satu strategi paling populer yang digunakan oleh banyak organisasi untuk meningkatkan tingkat kepuasan kerja karyawan (Harley et al., 2000; Scott et al., 2003; Pacheco dan Webber , 2016). Dari penjabaran literatur di atas, maka penulis membuat hipotesis sebagai berikut: 


\section{H6: Keterlibatan karyawan berpengaruh positif terhadap kepuasan kerja}

Madsen et al (2005) menemukan hubungan yang kuat antara komitmen organisasi dan kesiapan untuk berubah. Di antara faktor-faktor lain yang ditemukan memengaruhi kesiapan karyawan untuk berubah adalah komitmen manajer senior terhadap perubahan, kemampuan agen perubahan dan dukungan dari manajer langsung (Cinite et al., 2009). Hubungan yang kuat ditemukan antara kesiapan perubahan, kepuasan kerja, pekerjaan penuh waktu (tetap) dan peran staf non-klinis (Christl et al., 2010). Di dalam penelitian Al Hussami (2014), manajer perawat dengan kepuasan lebih pada pekerjaan dilaporkan memiliki kesiapan untuk perubahan yang lebih tinggi. Temuan yang sama ditemukan juga di pelatihan umum staf keperawatan di Australia (Christl et al., 2010). Demikian pula, korelasi tinggi ditemukan antara kepuasan dengan kepemimpinan dan kesiapan yang dirasakan untuk perubahan di penyedia perawatan kesehatan yang bekerja baik di pusat medis maupun departemen rawat jalan di Amerika Serikat (Helfrich et al., 2011). Dari penjabaran literatur di atas, maka penulis membuat hipotesis sebagai berikut:

\section{H7: Tingkat kepuasan kerja berpengaruh positif terhadap kesiapan karyawan} untuk berubah

Gambar 1 berikut adalah kerangka pemikiran yang menjadikan dasar dalam penelitian dan merupakan kerangka analisis dalam penelitian in.

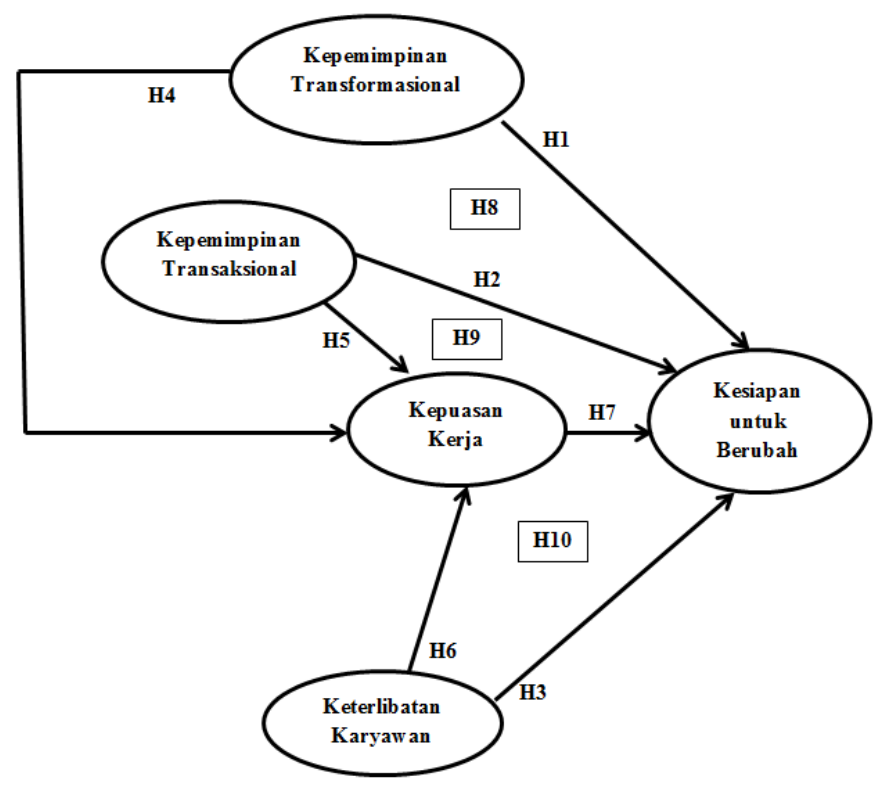

Gambar 1. Kerangka Hipotesis Penelitian

\section{METODE PENELITIAN}

Penelitian ini dimaksudkan untuk mengungkapkan gambaran mengenai pengaruh kepemimpinan, keterlibatan karyawan dan kepuasan kerja terhadap kesiapan karyawan untuk berubah dalam menghadapi perubahan organisasi. Berdasarkan permasalahan yang diteliti, maka metode penelitian yang digunakan dalam penelitian ini adalah metode deskriptif dengan pendekatan kuantitatif yang ditunjang oleh studi kepustakaan. Penelitian 
ini menggunakan metode deskriptif karena masalah yang diambil terpusat pada masalah aktual dan berada pada saat penelitian dilaksanakan dan menggunakan pendekatan kuantitatif dengan mendistribusikan angket yang berisi keterangan setiap variabel yang ingin diteliti dan kemudian dilakukan analisis penghitungan secara statistik. Dalam penelitian ini, populasi meliputi seluruh karyawan PT. Holcim Indonesia, Tbk, Cabang Cilacap yang berhubungan dengan kegiatan operasional pabrik yaitu departemen Produksi (63 orang), Maintenance (89 orang), Technical (19 orang) dan Support (76 orang) sehingga total populasi berjumlah 247 orang. Teknik pengambilan sampel dalam penelitian ini menggunakan proportional random sampling. Metode proportional random sampling memberikan peluang yang sama bersifat tak terbatas untuk dipilih menjadi sample yang diambil berdasarkan strata (kelas) dengan jumlah yang proporsional.

Alat pengukuran yang akan digunakan dalam penelitian ini menggunakan pengukuran data interval. Data yang bersifat interval dapat dihasilkan dengan suatu teknik, yaitu agree-disagree untuk digunakan variabel keterlibatan karyawan, kepuasan kerja dan kesiapan untuk dengan skala likert (Sugiyono, 2008). Untuk pengukuran kepemimpinan menggunakan Multifactor Leadership Questionnaire (MLQ) form yaitu $0=$ tidak sama sekali, 1 = sekali, 2 = kadang-kadang, 3 = sering, 4 = sering sekali. The Structural Equation Modelling (SEM) dari paket program AMOS digunakan dalam model dan pengujian hipotesis dengan alat bantu Software SPSS AMOS 21.0 for windows.

\section{HASIL DAN PEMBAHASAN}

\section{Uji Validitas Instrumen}

Perhitungan dilakukan dengan mengkorelasikan setiap skor item dengan skor total dengan menggunakan teknik Korelasi Pearson. Kriteria pengujian adalah jika koefisien korelasi rxy lebih besar dari nilai cut off sebesar 0.154 , maka item kuisioner dinyatakan valid dan dinyatakan sah sebagai alat pengumpul data. Berdasarkan hasil pengujian validitas instrumen pada 19 pertanyaan mengenai kesiapan untuk berubah, 28 pertanyaan mengenai kepemimpinan (transformasional dan transaksional), 32 pertanyaan mengenai keterlibatan karyawan dan 15 pertanyaan mengenai kepuasan kerja, diperoleh bahwa semua nilai koefisien korelasi lebih besar dari nilai cut off sebesar 0.154. Dengan demikian butir-butir pertanyaan di variabel tersebut dinyatakan valid dan dapat dipergunakan sebagai alat pengumpul data dalam penelitian ini.

\section{Uji Reliabilitas Instrumen}

Uji Reliabilitas Instrumen digunakan dengan tujuan untuk mengetahui konsistensi dari instrumen sebagai alat ukur, sehingga suatu pengukuran dapat dipercaya. Untuk menguji digunakan Alpha Cronbach,dimana suatu instrumen akan semakin reliable apabila koefisien alpha lebih dari 0.60. Dari hasil pengujian Alpha Cronbach untuk dimensi kesiapan untuk berubah menunjukkan nilai rata-rata 0.797 , untuk dimensi kepemimpinan transformasional menunjukkan nilai rata-rata 0.889, untuk dimensi kepemimpinan transaksional menunjukkan nilai rata-rata 0.735 , untuk dimensi keterlibatan karyawan menunjukkan nilai rata-rata 0.916 , sedangkan dimensi kepuasan kerja menunjukkan nilai rata-rata 0.666. Dari hasil tersebut diketahui bahwa nilai semua variabel mempunyai Alpha Cronbach yang lebih besar dari 0.6 , sehingga variabel tersebut dinyatakan handal dan layak dipergunakan sebagai alat pengumpul data. 


\section{Pengujian Hipotesis dan Hubungan Kausal}

Nilai C.R pengaruh Kepemimpinan Transformasional terhadap Kesiapan untuk Berubah sebesar $-1,488$ dengan nilai probability sebesar 0,137 . Nilai probability lebih besar dari significant alpha 5\% atau 0,05. Hal ini menunjukkan bahwa Kepemimpinan Transformasional tidak memiliki pengaruh yang signifikan terhadap Kesiapan untuk Berubah. Sehingga dapat disimpulkan bahwa hipotesis 1 belum terpenuhi.

Nilai C.R pengaruh Kepemimpinan Transaksional terhadap Kesiapan untuk Berubah sebesar -1,938 dengan nilai probability sebesar 0,053. Nilai probability lebih besar dari significant alpha 5\% atau 0,05. Hal ini menunjukkan bahwa Kepemimpinan Transaksional tidak memiliki pengaruh yang signifikan terhadap Kesiapan untuk Berubah. Sehingga dapat disimpulkan bahwa hipotesis 2 belum terpenuhi.

Nilai C.R pengaruh Kepemimpinan Transformasional terhadap Kepuasan Kerja sebesar $-1,025$ dengan nilai probability sebesar 0,305. Nilai probability lebih besar dari significant alpha 5\% atau 0,05. Hal ini menunjukkan bahwa Kepemimpinan Transformasional tidak memiliki pengaruh yang signifikan terhadap Kepuasan Kerja. Sehingga dapat disimpulkan bahwa hipotesis 3 belum terpenuhi.

Nilai C.R pengaruh Kepemimpinan Transaksional terhadap Kepuasan Kerja sebesar 2,805 dengan nilai probability sebesar 0,005 . Nilai probability lebih kecil dari significant alpha 5\% atau 0,05. Hal ini menunjukkan bahwa Kepemimpinan Transaksional memiliki pengaruh yang signifikan terhadap Kepuasan Kerja. Nilai Estimate sebesar 0,281 (positif). Ini menunjukkan bahwa Kepemimpinan Transaksional berpengaruh positif dan signifikan terhadap Kepuasan Kerja. Artinya semakin tinggi Kepemimpinan Transaksional maka cenderung dapat meningkatkan Kepuasan Kerja. Sehingga dapat disimpulkan bahwa hipotesis 4 terpenuhi.

Nilai C.R pengaruh Keterlibatan Karyawan terhadap Kesiapan untuk Berubah sebesar 5,004 dengan nilai probability sebesar 0,000. Nilai probability lebih kecil dari significant alpha 5\% atau 0,05. Hal ini menunjukkan bahwa Keterlibatan Karyawan memiliki pengaruh yang signifikan terhadap Kesiapan untuk Berubah. Nilai Estimate sebesar 0,950 (positif). Ini menunjukkan bahwa Keterlibatan Karyawan berpengaruh positif dan signifikan terhadap Kesiapan untuk Berubah. Artinya semakin tinggi Keterlibatan Karyawan maka cenderung dapat meningkatkan Kesiapan untuk Berubah. Sehingga dapat disimpulkan bahwa hipotesis 5 terpenuhi.

Nilai C.R pengaruh Keterlibatan Karyawan terhadap Kepuasan Kerja sebesar 3,074 dengan nilai probability sebesar 0,002 . Nilai probability lebih kecil dari significant alpha $5 \%$ atau 0,05. Hal ini menunjukkan bahwa Keterlibatan Karyawan memiliki pengaruh yang signifikan terhadap Kepuasan Kerja. Nilai Estimate sebesar 0,876 (positif). Ini menunjukkan bahwa Keterlibatan Karyawan berpengaruh positif dan signifikan terhadap Kepuasan Kerja. Artinya semakin tinggi Keterlibatan Karyawan maka cenderung dapat meningkatkan Kepuasan Kerja. Sehingga dapat disimpulkan bahwa hipotesis 6 terpenuhi.

Nilai C.R pengaruh Kepuasan Kerja terhadap Kesiapan untuk Berubah sebesar 2,51 dengan nilai probability sebesar 0,012 . Nilai probability lebih kecil dari significant alpha $5 \%$ atau 0,05. Hal ini menunjukkan bahwa Kepuasan Kerja memiliki pengaruh yang signifikan terhadap Kesiapan untuk Berubah. Nilai Estimate sebesar 0,142 (positif). Ini menunjukkan bahwa Kepuasan Kerja berpengaruh positif dan signifikan terhadap Kesiapan untuk Berubah. Artinya semakin tinggi Kepuasan Kerja maka cenderung dapat meningkatkan Kesiapan untuk Berubah. Sehingga dapat disimpulkan bahwa hipotesis 7 terpenuhi. 
Nilai C.R pengaruh Kepemimpinan Transformasional terhadap Keterlibatan Karyawan sebesar 13,939 dengan nilai probability sebesar 0,000. Nilai probability lebih kecil dari significant alpha 5\% atau 0,05. Hal ini menunjukkan bahwa Kepemimpinan Transformasional memiliki pengaruh yang signifikan terhadap Keterlibatan Karyawan. Nilai Estimate sebesar 0,525 (positif). Ini menunjukkan bahwa Kepemimpinan Transformasional berpengaruh positif dan signifikan terhadap Keterlibatan Karyawan. Artinya semakin tinggi Kepemimpinan Transformasional maka cenderung dapat meningkatkan Keterlibatan Karyawan. Sehingga dapat disimpulkan bahwa hipotesis 8 terpenuhi.

Nilai C.R pengaruh Kepemimpinan Transformasional terhadap Kesiapan untuk Berubah melalui Kepuasan Kerja sebesar -0,810 dengan nilai probability sebesar 0,210. Nilai probability lebih besar dari significant alpha 5\% atau 0,05. Hal ini menunjukkan bahwa Kepemimpinan Transformasional memiliki pengaruh yang signifikan terhadap Kesiapan untuk Berubah melalui Kepuasan Kerja. Sehingga dapat disimpulkan bahwa hipotesis 9 tidak terpenuhi.

Nilai C.R pengaruh Kepemimpinan Transaksional terhadap Kesiapan untuk Berubah melalui Kepuasan Kerja sebesar 1,871 dengan nilai probability sebesar 0,031. Nilai probability lebih kecil dari significant alpha 5\% atau 0,05. Hal ini menunjukkan bahwa Kepemimpinan Transaksional memiliki pengaruh yang signifikan terhadap Kesiapan untuk Berubah melalui Kepuasan Kerja. Nilai estimate sebesar 0,042 (positif) menunjukkan bahwa peeningkatan kepuasan kerja yang disebabkan oleh peningkatan kepemimpinan transaksional, maka cenderung dapat meningkatkan Kesiapan untuk Berubah. Sehingga dapat disimpulkan bahwa hipotesis 10 terpenuhi.

Nilai C.R pengaruh Keterlibatan Karyawan terhadap Kesiapan untuk Berubah melalui Kepuasan Kerja sebesar 1,896 dengan nilai probability sebesar 0,030. Nilai probability lebih kecil dari significant alpha 5\% atau 0,05. Hal ini menunjukkan bahwa Keterlibatan Karyawan memiliki pengaruh yang signifikan terhadap Kesiapan untuk Berubah melalui Kepuasan Kerja. Nilai estimate sebesar 0,124 (positif) menunjukkan bahwa peeningkatan kepuasan kerja yang disebabkan oleh peningkatan Keterlibatan Karyawan, maka cenderung dapat meningkatkan Kesiapan untuk Berubah. Sehingga dapat disimpulkan bahwa hipotesis 11 terpenuhi.

\section{Pembahasan Hasil Penelitian \\ Pengaruh kepemimpinan Transformational terhadap kesiapan untuk berubah dalam menghadapi perubahan organisasi}

Selama proses perubahan organisasi, dimensi kepemimpinan baik transformational maupun transaksional tidak terlihat pada leader - leader yang berada di Pabrik Cilacap karena semua kebijakan strategis ditetapkan oleh manajemen puncak dan melalui hierarki keputusan Top - Down. Perubahan - perubahan tersebut diprakarsai oleh tim manajemen puncak (CEO, BOD dan jajarannya) dan tidak melibatkan manajemen di level pabrik. Manajemen di level pabrik (supervisor, manajer area, manajer senior, ataupun general manager) hanya merupakan perpanjangan tangan dari kebijakan yang diputuskan oleh manajemen puncak dan mereka memiliki keterbatasan informasi yang dapat disampaikan kepada karyawan yang menjadi bawahannya. Informasi tentang kebijakan perusahaan sangat terbatas dan tidak dikomunikasikan dengan baik sampai pada level karyawan yang paling bawah. Informasi yang diterima lebih banyak diperoleh dari Serikat pekerja (union) yang secara intens melakukan pembicaraan dengan manajemen terkait kondisi perusahaan, hak- hak karyawan maupun kebijakan - kebijakan perusahaan yang baru. Salah satu 
dimensi transformasional (Inspirasi motivasi) dalam pernyataan "Menyuarakan visi masa depan yang menjanjikan" memiliki persepsi rendah dari responden dikarenakan para leader / atasan tidak memiliki informasi yang cukup terkait kondisi perusahaan saat itu.

Menurut Robbins dan Coulter (2004), individu menolak perubahan dapat disebabkan oleh beberapa alasan seperti ketidakpastian, melakukan di luar kebiasaan, takut kehilangan sesuatu yang telah dimiliki, dan keyakinan individu bahwa perubahan tidak sejalan dengan tujuan dan kepentingan organisasi. Hal ini sejalan dengan penelitian sebelumnya dimana pada lingkungan yang kurang stabil, anggota organisasi mungkin hanya menerima perubahan yang secara langsung menguntungkan mereka dan dalam konteks non-reseptif, bahkan kepemimpinan transformasional gagal menghasilkan komitmen anggota organisasi, tidak peduli seberapa menarik dan tepat visi yang dibawanya (Avolio dan Bass, 1988). Hasil penelitian ini tidak sejalan dengan penelitian sebelumnya yang menyatakan bahwa kepemimpinan transformasional memiliki pengaruh yang positif terhadap kesiapan untuk berubah yang membuat peneliti membuat hipotesis tersebut.

\section{Pengaruh kepemimpinan Transaksional terhadap kesiapan untuk berubah dalam menghadapi perubahan organisasi}

Salah satu kebijakan yang dibuat selama proses perubahan organisasi di PT Holcim Indonesia adalah adanya perubahan penilaian kinerja akhir tahun dan mulai diberlakukannya penilaian kinerja "Total Reward" pada tahun 2016. Program Total reward bertujuan untuk memberikan apresiasi dan penilaian terhadap kinerja karyawan dimana hasil penilaian atau appraisal tersebut berimplifikasi terhadap besaran bonus tahunan \& kenaikan salary masing - masing karyawan. Sebelum tahun 2016, bonus tahunan dibagikan secara merata sesuai dengan kinerja perusahaan (Actual vs Budget EBITDA) dan tidak terpengaruh oleh penilaian individu. Hal - hal tersebut menyebabkan adanya kesenjangan di antara masing - masing karyawan yang menganggap penilaian kinerja bersifat subjektif oleh atasan dan tidak tergantung pada kinerja individu. Pemberian bonus tahunan dan kenaikan gaji yang tidak sama menyebabkan kecemburuan bagi karyawan sehingga suasana kerja menjadi kurang kondusif. Karyawan merasa bahwa kinerja nya tidak dihargai dan penilaian atasan cenderung subjektif. Kondisi tersebut diatas menyebabkan karyawan merasa bahwa mereka tidak mendapatkan imbalan yang sesuai atas kinerja yang telah dilakukan yang pada akhirnya dapat memengaruhi proses kesiapan karyawan untuk Berubah. Hal ini sesuai dengan penelitian sebelumnya dimana Meyer dan Herscovitch (2001), Walumbwa et al. (2008) menyatakan bahwa karyawan akan lebih berkomitmen untuk organisasi apabila imbalan kontingen (contingen reward) diberikan sebagai imbalan atas kinerja mereka.

\section{Pengaruh Kepemimpinan Tranformasional terhadap Kepuasan Kerja}

Dimensi kepemimpinan transformasional yang berhubungan dengan kepuasan kerja dimana mendapatkan persepsi rendah adalah pertimbangan individu (individual consideration) seperti kesempatan untuk mendapatkan pengetahuan dan pelatihan, pengakuan atas kinerja, pertimbangan akan aspirasi dan kemampuan individu. Lingkungan kerja di PT Holcim Indonesia pabrik Cilacap mengedepankan kerjasama, partisipasi dan pemberdayaan karyawan dalam melakukan pekerjaan sehari hari dan dapat dikategorikan pada budaya organisasi kelompok (Clan/group culture). Hal tersebut diindikasikan dimana karyawan merasa nyaman bekerja dengan rekan sekerja dan dapat saling berbagi tanggung jawab. Karyawan juga memiliki sikap yang loyal dan komitmen yang tinggi terhadap 
perusahaan. Cameron dan Quinn (1999, hlm. 58) menyatakan bahwa sebuah organisasi yang didominasi oleh budaya "kelompok" menekankan pada manfaat jangka panjang dari pengembangan sumber daya manusia (mis. pelatihan) dan sangat mementingkan kohesi dan moral. Jadi walaupun karyawan tidak mendapatkan hal yang positif dari salah satu dimensi kepemimpinan transformasional (pertimbangan individu), tetapi karyawan merasa mendapatkan kepuasan kerja melalui dimensi rekan sekerja dan pekerjaaan itu sendiri.

\section{Pengaruh Kepemimpinan Transaksional terhadap Kepuasan Kerja}

Dimensi kepemimpinan transaksional yang berhubungan dengan kepuasan kerja adalah proses pemberian imbalan (contingency reward) baik yang berwujud (gaji dan tunjangan) maupun yang tidak berwujud (pengakuan atau penghargaan), manajemen perkecualian aktif serta pasif yang berpengaruh positif dengan beberapa dimensi kepuasan kerja seperti supervisor dan gaji. Hasil penelitian ini sejalan dengan beberapa penelitian sebelumnya yang dilakukan oleh Gaspar (1992); Patterson, Fuller dan Stringer (1995); dan Bass (1998). Mereka menyampaikan bahwa kepemimpinan transaksional berpengaruh positif terhadap kepuasan kerja.

\section{Pengaruh Keterlibatan Kerja terhadap Kesiapan untuk Berubah}

Dimensi keterlibatan karyawan yang meliputi power sharing, information sharing, reward dan knowledge sharing (PIRK) dirasakan oleh karyawan Holcim sangat positif. Seperti yang sudah dijelaskan pembahasan hipotesis sebelumnya bahwa lingkungan kerja di PT Holcim Indonesia pabrik cilacap mengedepankan kerjasama, partisipasi dan pemberdayaan karyawan dalam melakukan pekerjaan dan dikategorikan pada budaya organisasi kelompok (Clan/group culture). Menurut penelitian, budaya organisasi (Organizational change) diakui menjadi salah satu faktor paling penting yang dapat mendorong atau menurunkan kesiapan karyawan untuk berubah (Armenakis et al., 1993; Weiner, 2009; Jones et al., 2005; Choi dan Ruona, 2011). Keterlibatan karyawan dapat juga dilakukan melalui perwakilan di serikat pekerja (union) guna mendapatkan informasi kondisi perusahaan dan kepastian mendapatkan imbalan yang sesuai dengan kinerja serta hak dan kewajiban karyawan yang tertuang dalam Perjanjian Kerja Bersama (PKB). Keterlibatan karyawan dalam perubahan dapat mengurangi resistensi karena memahami kebutuhan untuk perubahan dan kemampuan yang dirasakan untuk berubah sangatlah penting (Armenakis et al., 1993; Wanberg dan Banas, 2000). Penelitian sebelumnya menyatakan bahwa peran agen perubahan, proses yang tepat, partisipasi, keyakinan, lingkungan, keadilan dan komitmen terkait dengan kesiapan karyawan (Hanpachern et al., 1998; Eby et al., 2000; Cunningham et al., 2002; Madsen et al., 2005; Rafferty dan Simons, 2006; Bermerth et al., 2007).

\section{Pengaruh Keterlibatan Kerja terhadap Kepuasan Kerja}

Semua dimensi keterlibatan kerja berpengaruh terhadap kepuasan kerja dimana dalam penelitian ini dimensi power sharing mendapatkan persepsi tertinggi terkait kewenangan, kemudian dukungan dari orang lain baik rekan sekerja maupun supervisor serta partisipasi. Penelitian sebelumnya menyatakan bahwa melibatkan karyawan untuk berpartisipasi dalam keputusan yang berhubungan dengan pekerjaan adalah salah satu strategi paling populer yang digunakan oleh banyak organisasi untuk meningkatkan tingkat kepuasan kerja karyawan (Harley et al., 2000; Scott et al., 2003; Pacheco dan Webber , 2016). Zatzick dan Iverson (2012) dalam penelitiannya menemukan bahwa ada hubungan postif antara 
keterlibatan karyawan terhadap kepuasan kerja, dan juga penelitian oleh PUN et al ( 2001) menghasilkan bahwa ada hubungan postif antara keterlibatan karyawan terhadap kepuasan kerja.

\section{Pengaruh Kepuasan Kerja terhadap Kesiapan untuk Berubah}

Responden memberikan persepsi yang positif pada semua dimensi kepuasan kerja seperti promosi, rekan sekerja, supervisor, pekerjaan itu sendiri maupun gaji. Kepuasan kerja yang tinggi ini berkorelasi positif dengan dimensi kesiapan untuk berubah yang tinggi juga di lingkungan kerja PT Holcim Indonesia pabrik Cilacap. Hal ini sejalan dengan penelitian sebelumnya dimana ada hubungan kuat yang ditemukan antara kesiapan perubahan, kepuasan kerja, pekerjaan penuh waktu (tetap) dan peran staf non-klinis (Christl et al., 2010). Di dalam penelitian Al Hussami (2014), manajer perawat dengan kepuasan lebih pada pekerjaan dilaporkan memiliki kesiapan untuk perubahan yang lebih tinggi. Korelasi tinggi ditemukan antara kepuasan dengan kepemimpinan dan kesiapan yang dirasakan untuk perubahan di penyedia perawatan kesehatan yang bekerja baik di pusat medis maupun departemen rawat jalan di Amerika Serikat (Helfrich et al., 2011).

\section{Pengaruh Kepemimpinan Tranformasional terhadap Keterlibatan Karyawan}

Hipotesis ini ditambahkan karena hipotesis sebelumnya mengenai pengaruh kepemimpinan transformasional terhadap kepuasan kerja ataupun terhadap kesiapan untuk berubah ditolak tetapi jika melihat rata-rata pengisian survey kuesioner yang tinggi, hal ini menunjukan adanya kepemimpinan transformasional pada para pimpinan di lingkungan PT Holcim Indonesia pabrik Cilacap. Hasil penelitian ini sejalan dengan penelitian-penelitian sebelumnya dimana Lawler et al berpendapat bahwa manajemen puncak harus belajar untuk mempercayai orang-orang mereka dan memberi mereka kekuatan untuk menjadi inovatif dan membawa perubahan. Dalam dimensi kepemimpinan transformasional (karisma-pengaruh ideal, inspirasi motivasi, stimulasi intelektual, dan pertimbangan individu) mendorong karyawan untuk lebih terlibat dalam pekerjaan mereka guna mencapai tujuan yang telah ditetapkan. Atasan juga bertanggung jawab untuk memberikan pengarahan, pengetahuan dan kesempatan bawahan untuk mengembangkan diri.

\section{Pengaruh Kepemimpinan Tranformasional terhadap Kesiapan untuk Berubah yang} dipengaruhi oleh Variabel Kepuasan Kerja

Seperti yang sudah dijelaskan di hipotesis sebelumnya, responden menganggap ada dimensi dari kepemimpinan transformasional yaitu individual consideration yang tidak berjalan dengan baik dan pada dimensi kepuasan kerja dimana jarang terjadi promosi di tempat kerja tetapi hal tersebut tidak berpengaruh terhadap tingkat kesiapan untuk berubah bagi karyawan PT Holcim Indonesia pabrik cilacap. Hasil penelitian ini tidak sejalan dengan penelitian sebelumnya yang mengaitkan antara kepemimpinan, kepuasan kerja dan kesiapan untuk berubah seperti Madsen et al (2005) yang menemukan hubungan kuat antara komitmen organisasi dan kesiapan untuk berubah. Di antara faktor-faktor lain yang ditemukan memengaruhi kesiapan karyawan untuk berubah adalah komitmen manajer senior terhadap perubahan, kemampuan agen perubahan dan dukungan dari manajer langsung (Cinite et al., 2009). Hubungan yang kuat ditemukan antara kesiapan perubahan, kepuasan kerja, pekerjaan penuh waktu (tetap) dan peran staf non-klinis (Christl et al., 2010). 


\section{Pengaruh Kepemimpinan Transaksional terhadap Kesiapan untuk Berubah yang dipengaruhi oleh Variabel Kepuasan Kerja}

Adanya korelasi positif antara dimensi kepemimpinan transaksional yaitu contingency reward dengan kepuasan kerja yang dirasakan oleh karyawan sangat berpengaruh terhadap kesiapan untuk berubah. Dukungan supervisor atau atasan, pelatihan dan keterampilan yang diperoleh serta kesesuaian antara imbalan dengan tanggung jawab yang diemban semakin meningkatkan kesiapan karyawan untuk berubah dalam menghadapi perubahan organisasi. Hal ini sejalan dengan penelitian yang menyatakan bahwa faktorfaktor lain yang ditemukan memengaruhi kesiapan karyawan untuk berubah adalah komitmen manajer senior terhadap perubahan, kemampuan agen perubahan dan dukungan dari manajer langsung (Cinite et al., 2009). Hubungan yang kuat ditemukan antara kesiapan perubahan, kepuasan kerja, pekerjaan penuh waktu (tetap) dan peran staf non-klinis (Christl et al., 2010).

\section{Pengaruh Keterlibatan Karyawan terhadap Kesiapan untuk Berubah yang dipengaruhi oleh Variabel Kepuasan Kerja}

Seperti yang telah disebutkan sebelumnya, ada korelasi antara keterlibatan karyawan dan kepuasan kerja yang dinilai positif oleh responden sehingga secara tidak langsung dapat meningkatkan kesiapan karyawan untuk berubah. Fungsi dan kepercayaan kepada serikat pekerja (union) dalam memberikan informasi terkini tentang kondisi perusahaan, perjuangan hak-hak karyawan dan penciptaan suasana kerja yang kondusif dapat meningkatkan kesiapan karyawan untuk berubah.

\section{KESIMPULAN}

Kepemimpinan transformasional tidak berpengaruh secara signifikan terhadap kesiapan karyawan untuk berubah selama proses perubahan organisasi yang terjadi di PT Holcim Indonesia. Hal ini dimungkinkan karena kurangnya komunikasi dari atasan ke bawahan terkait perubahan organisasi yang terjadi sehingga bawahan kurang dapat menerima informasi terkini terkait kondisi perusahaan, kebijakan-kebijakan baru maupun masa depan perusahaan di waktu mendatang. Keterbatasan informasi yang diperoleh dari atasan menyebabkan salah satu dimensi kepemimpinan transformasional (insprirasi motivasi) menjadi komponen yang paling tidak berpengaruh karena atasan tidak dapat membangun optimisme dan menyuarakan visi masa depan yang menjanjikan.

Dalam dimensi kepemimpinan transaksional, faktor yang paling tidak berpengaruh adalah manajemen dengan perkecualian pasif (MBE-P) untuk pernyataan "Menunjukkan keyakinan jika sesuatu tidak ada yang rusak, jangan diperbaiki" dan "Mengarahkan perhatian terhadap kegagalan dalam mencapai standard". Diharapkan kedepannya, para pimpinan lebih berpartisipasi aktif dalam mencari akar masalah yang menyebabkan kegagalan proses produksi sehingga penyebab kegagalan dapat dieliminasi dan tidak berulang. PT Holcim Indonesia mempunyai tools yang dipakai untuk mencari akar masalah dan solusi jika terjadi kegagalan proses produksi yaitu RFCA (Root Failure and Cause Analysis). Partisipasi para pimpinan dalam menyukseskan program ini sangat diperlukan dan konsisten dilaksanakan setiap terjadi kegagalan proses produksi sehingga target perusahaan yaitu NAI dan MTBF dapat tercapai.

Keterlibatan karyawan yang meliputi dimensi power sharing, information sharing, reward dan knowledge sangat berpengaruh terhadap kepuasan kerja dan kesiapan untuk berubah bagi karyawan PT holcim pabrik Cilacap. Karyawan merasa dilibatkan dalam pengambilan keputusan yang menyangkut hak dan kewajiban sebagai tenaga kerja melalui perwakilan atau serikat pekerja. Dalam hal pekerjaan sehari -hari, karyawan juga merasa mendapatkan wewenang yang cukup dan sesuai dengan tanggung jawabnya. Hal yang 
menjadi perhatian bagi manajemen adalah karyawan merasa jarang mendapatkan kesempatan promosi dalam struktur organisasi yang sekarang dan mereka merasa bahwa jika mereka melakukan pekerjan dengan baik, kecil kemungkinan mereka akan dipromosikan. Hal yang sama juga ditemukan pada dimensi kepuasaan kerja dimana mereka memberikan penilaian yang rendah di dimensi promosi.

Hal yang paling menonjol baik dalam dimensi keterlibatan karyawan dan kepuasan kerja adalah karyawan di lingkungan PT Holcim Indonesia pabrik cilacap merasa nyaman dan senang bekerja sama dengan rekan -rekan sekerja dan senang dengan tingkat tanggung jawab yang mereka emban saat ini. Faktor ini sangat berpengaruh terhadap tingginya kesiapan karyawan untuk berubah karena mereka merasa senasib sepenanggungan dan siap menghadapi apa yang terjadi di masa mendatang.

Implikasi manajemen yang perlu dikembangkan adalah perlunya keterbukaan informasi dan komunikasi dua arah antara atasan dan bawahan terhadap proses perubahan organisasi agar bawahan dapat melaksanakan perubahan yang diusulkan, menyadari bahwa perubahan ini sudah tepat untuk perusahaan dan menguntungkan bagi semua karyawan, sedangkan implikasi akademik untuk penelitian ini adalah untuk memperkaya kajian pustaka yang telah ada terkait dengan kesiapan untuk berubah yang dikaitkan dengan faktor kepemimpinan, keterlibatan karyawan dan kepuasan kerja.

Keterbatasan yang ada dalam penelitian ini adalah ada 2 kriteria yang tidak dipenuhi dalam model penelitian ini (GFI dan AGFI) yang masuk dalam kategori "Marginal Fit" dan rentang waktu pengambilan data kuesioner berada pada masa transisi pergantian kepemilikan dari PT Holcim Indonesis Tbk kepada PT Semen Indonesia Tbk sehingga peneliti merasa peristiwa itu dapat memengaruhi pengisian kuesioner. Faktor komitmen organisasi, loyalitas karyawan, tipe budaya organisasi, ataupun LMX (Leader-Member Exchange) dapat dilakukan penelitian di masa mendatang untuk melihat pengaruhnya terhadap kesiapan untuk berubah. Lamanya waktu bekerja di suatu perusahaan dapat juga menjadi predictor kuat yang memengaruhi kesiapan untuk berubah.

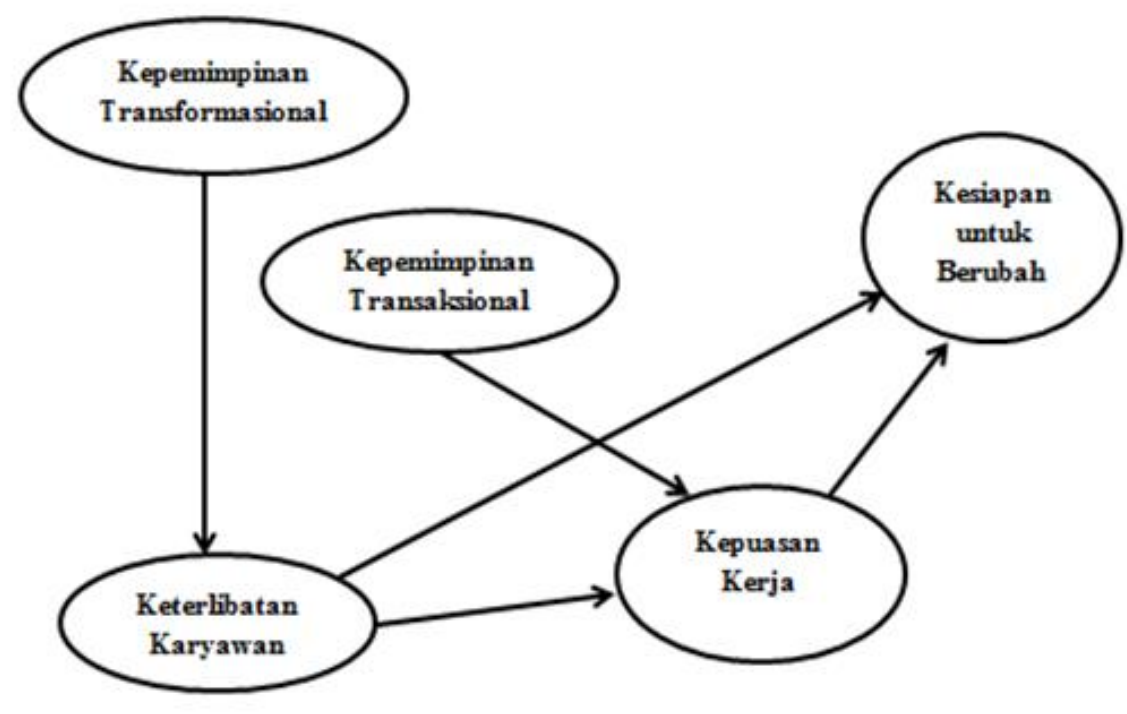

Gambar 2. Diagram Alur Penelitian

\section{DAFTAR PUSTAKA}

Aarons, G. (2006), "Transformational and transactional leadership: association with attitudes toward evidence-based practice", Psychiatric Services, Vol. 57 No. 8, p. 1162. 
Abdolshah, M. and Abdolshah, S. (2011), "Barriers to the successful implementation of TQM in Iranian manufacturing organizations", International Journal of Productivity and Quality Management, Vol. 7 No. 3, pp. 358-373.

Abdul Rashid, M.Z., Sambasivan, M. and Abdul Rahman, M. (2004), "The influence of organizational culture on attitudes toward organizational change", Leadership and Organization Development Journal, Vol. 25 No. 2, pp. 161-179.

Al-Hussami, M., Darawad, M., Saleh, A. and Hayajneh, F. (2014), The effects of leadership competencies and quality of work on the perceived readiness for organizational change among nurse managers, International Journal of Nursing Practice, Vol. 20 No. 1, pp. 1751-1879.

Arikunto, Suharsimi. 2005. Manajemen Penelitian. Jakarta. Rineka Cipta

Armenakis, A.A., Harris, S.G. and Mossholder, K.W. (1993), "Creating readiness for organizational change", Human Relations, Vol. 46 No. 6, pp. 681-703.

Backer, T. (1995), "Assessing and enhancing readiness for change: implications for technology transfer", NIDA Research Monograph, Vol. 155, pp. 21-41.

Bass, BM, \& Avolio, B.J. (1990), Transformational Leadership Development: Manual for the Multifactor leadership Questionnaire California: Consulting Psychologists Press

Bass, BM, \&Avolio, B.J. (1995), Improving Organizational Effectiveness through Transformational Leadership.Thousand Oaks SAGE Publications, Inc.

Bass, B.M. (1998), Transformational Leadership: Industrial Millitary

Bass B.M. (1985a), Leadership and Performance beyond Expectations, Harperand Row, New York, NY Educational Impact LAWRENCE ERLBAUM ASSOCIATES, PUBLISHER Mahwah, New Jersey

Bernerth, J., Armenakis, H.S., Field, H.S. and Walker, H.J. (2007), "Justice, cynicism, and commitment: a study of important organizational change variables", The Journal of Applied Behavioral Science, Vol. 43 No. 3, pp. 303-26

Biswas, S. 2012. Impact of Psychological Climate \& Transformational Leadership on Employee Performance, The Indian Journal of Industrial Relations, vol.48.No.1 pp.105-115

Bommer, W., Rich, G. and Rubin, R. (2005), "Changing attitudes about change: longitudinal effects of transformational leader behavior on employee cynicism about organizational change", Journal of Organizational Behavior, Vol. 26 No. 7, pp. 733-753.

By, R.T. (2007), "Ready or not”, Journal of Change Management, Vol. 7 No. 1, pp. 3-11.

Choi, M. and Ruona, W.E.A. (2011), "Individual readiness for organizational change and its implications for human resource and organization development", Human Resource Development Review, Vol. 10 No. 1, pp. 46-73.

Christl, B., Harris, M., Jayasinghe, U., Proudfoot, J., Taggart, J. and Tan, J. (2010), "Readiness for organizational change among general practice staff", Quality and Safety in Health Care, Vol. 19 No. 5, pp. 1-4

Cinite, I., Duxbury, L.E. and Higgins, C. (2009), "Measurement of perceived organizational readiness for change in the public sector", British Journal of Management, Vol. 20 No. 2, pp. 265-277

Clegg, C. and Walsh, S. (2004), "Change management: time for a change", European Journal of Work and Organizational Psychology, Vol. 13 No. 2, pp. 217-223.

Cotton, J.L. (1993). Employee Involvement: Methods for improving Performance and Work Attitudes, SAGE Publications, London

Cunningham, I and Hyman. J. (1999). The poverty of empowerment? A critical case study, Personal review, Vol. 28 No. 3, pp. 192-207

Cunningham, C.E., Woodward, C.A., Shannon, H.S. and MacIntosh, J. (2002), "Readiness for organizational change: a longitudinal study of workplace, psychological and behavioural correlates", Journal of Occupational and Organizational Psychology, Vol. 75 No. 4, pp. 377-92. 
Dale. B. and Cooper, C. (1992), Total Quality and Human Resources, an Executive Guide Blackwell Publishers, Oxford, UK

Delaney, J.T. (1996), "Workplace cooperation: current problem new approach, Jounal of labour research, Winter Vol 17 no.1, pp. 45-63

Devereaux, M., Drynan, A., Lowry, S., MacLennan, D., Figdor, M., Fancott, C. and Sinclair, L. (2006), "Evaluating organizational readiness for change: a preliminary mixed-model assessment of an interprofessional rehabilitation hospital", Healthcare Quarterly, Vol. 9 No. 4, pp. 66-74.

Eby, L.T., Adams, D.M., Russell, J.E.A. and Gaby, S.H. (2000), "Perceptions of organizational readiness for change: factors related to employees' reactions to the implementation of team based selling", Human Relations, Vol. 53 No. 3, pp. 419-442.

Emery, C. and Barker, K. (2007), "The effect of transactional and transformational leadership styles on the organizational commitment and job satisfaction of customer contact personnel", Journal of Organizational Culture, Communications and Conflict, Vol. 11 No. 1, pp. 77-90.

Felicia Dewi Wibowo (2008), Analisa Pengaruh Kepemimpinan dan Pengembangan Karir Terhadap Komitmen Organisasi dalam Meningkatkan Kinerja Karyawan (Studi Kasus: PT. Bank Maspion Indonesia Cabang Semarang). Penerbit Universitas Diponegoro Semarang

Ferdinand Augusty (2006), Structural Equation Modeling dalam Penelitian Manajemen, Badan Penerbit Universitas Diponegoro Semarang

Fuentes-Henriquez, F. and Del Sol, P. (2012), "Analogical foundation of the scope of organizational change", Journal of Organizational Change Management, Vol. 25 No. 1, pp. 163-185.

Ghozali, Imam. 2013. Analisis Aplikasi Multivariate Dengan Program IBM SPSS 20. Semarang: Badan Penerbit Universitas Diponegoro.

Gill, R. (2002), "Change management-or change leadership?", Journal of Change Management, Vol. 3 No. 4, pp. 307-318.

Gilley, A., McMillan, H. and Gilley, J. (2009), "Organizational change and characteristics of leadership effectiveness", Journal of Leadership \& Organizational Studies, Vol. 16 No. 1, pp. 38-47.

Gumusluoglu, L. and Ilsev, A. (2009), "Transformational leadership, creativity, and organizational innovation", Journal of Business Research, Vol. 62 No. 4, pp. 461-473.

Hanpachern, C., Morgan, G.A. and Griego, O.V. (1998), "An extension of the theory of margin: a framework for assessing readiness for change", Human Resource Development Quarterly, Vol. 9 No. 4, pp. 339-50.

Harley, B., Ramsey, H., and Scholarios, D. (2000). "Employee Direct Participation in Britain and Australia: Evidence from AWIRS95 and WERS98", Asia Pacific Journal of Human Resources, 38(2): 42-54.

Helfrich, C., Blevins, D., Smith, J., Kelly, A., Hogan, D., Hagedorn, H., Dubbert, P.M. and Sales, A.E. (2011), "Predicting implementation from organizational readiness for change: a study protocol", Implementation Science, Vol. 6, p. 76.

Hill, N.S., Seo, M.G., Kang, J.H. and Taylor, S.H. (2012), "Building employee commitment to change across organizational levels: the influence of hierarchical distance and direct managers' transformational leadership", Organizational Science, Vol. 23 No. 3, pp. 758-77.

Holt, D.T., Armenakis, A.A., Field, H.S. and Harris, S.G. (2007), "Readiness for organizational change: the systematic development of a scale", The Journal of Applied Behavioural Science, Vol. 43 No. 2, pp. 232-255.

Huy, N.Q. (2002), "Emotional balancing of organizational continuity and radical change: the contribution of middle managers", Administrative Science Quarterly, Vol. 47 No. 1, pp. 31-69.

Ingersoll, G., Kirsch, J., Merk, S. and Lightfoot, J. (2000), "Relationship of organizational culture and readiness for change to employee commitment to the organization", Journal of Nursing Administration, Vol. 30 No. 1, pp. 11-20. 
Pengaruh Kepemimpinan, Keterlibatan Karyawan dan Kepuasan Kerja terhadap Kesiapan untuk Berubah dalam Menghadapi Perubahan Organisasi

Jones, R.A., Jimmieson, N.L. and Griffiths, A. (2005), "The impact of organizational culture and reshaping capabilities on change implementation success: the mediating role of readiness for change", Journal of Management Studies, Vol. 42 No. 2, pp. 361-386.

Judith R. Gordon (2001) Organizational Behavior: A Diagnostic Approach Fundamentals, Human Resource Management Seventh Edition

Klein, K.J. and Sorra, J.S. (1996), "The challenge of innovation implementation", Academy of Management Review, Vol. 21 No. 4, pp. 1055-1080.

Kotter, J.P. (1995), "Why transformation efforts fail”, Harvard Business Review, Vol. 73 No. 2, pp. 5967.

Lawler, E.E. III (1994), "Total quality management and employee involvement: Are they compatible?" Academy of Management Executive, Vol.8, No.1, pp.68-76

Lawler III EE. Mohrman, SA. and Ledford Jr. G.E (1993), Creative High Performance Organizations Practices and Results of Employee Achievement and Total husliry Management in Fortune 1000 Companies. Jossey Basx, San Francico, CA

Lawson, E. and Price, C. (2003), "The psychology of change management", The McKinsey Quarterly, No. 2, pp. 30-39.

Lewin, K. (1951), Field Theory in Social Science - Selected Theoretical Papers, Harper \& Row, New York, NY

Lo, M., Ramayah, T. and Run, E. (2010), “Does transformational leadership style foster commitment to change? The case of higher education in Malaysia”, Procedia-Social and Behavioral Sciences, Vol. 2 No. 2, pp. 5384-5388.

Madsen, S.R., Miller, D. and John, C.R. (2005), "Readiness for organizational change: do organizational commitment and social relationships in the workplace make a difference?", Human Resource Development Quarterly, Vol. 16 No. 2, pp. 213-33.

Mariam, R., 2009. Pengaruh Gaya Kepemimpinan dan Budaya Organisasi Terhadap Kinerja Karyawan Melalui Kepuasan Kerja Karyawan Sebagai Variabel Intervening Studi Pada Kantor Pusat PT.Asuransi Jasa Indonesia (Persero), Penerbit Universitas Diponegoro Semarang, 36 dan 83 hlm.

Mas'ud, F. 2005. Survai Diagnosis Organisasional (Konsep dan Aplikasi), Badan Penerbit Universitas Diponegoro.

Meyer, J.P. and Herscovitch, L.(2001), "Commitment in the workplace: Toward a general model", Human Resource Management Review, Vol.11, No. 3, pp. 299-326.

Mohammed, K., Othman, J. and Silva, J. (2012), "Social demographic factors that influence transformational leadership styles among top management in selected organizations in malaysia", Asian Social Science, Vol. 8 No. 13, p. 51.

Munir, F., Nielsen, K., Garde, A., Albertsen, K. and Carneiro, I. (2012), "Mediating the effects of worklife conflict between transformational leadership and health-care workers' job satisfaction and psychological wellbeing", Journal of Nursing Management, Vol. 20 No. 4, pp. 512-521.

Murphy, L. (2005), "Transformational leadership: a cascading chain reaction", Journal of Nursing Management, Vol. 13 No. 2, pp. 128-136.

Nordin, N. (2011), “The influence of emotional intelligence, leadership behaviour and organizational commitment on organizational readiness for change in higher learning institution", ProcediaSocial and Behavioral Sciences, Vol. 29, pp. 129-138.

Ooshuizen, G.J. and du Toit AS.A. (1999). Participative management in academic library sevices, Library Management. Vol. 20 No. 4, pp. 213-220

Pacheco, G. and Webber, D. (2016). "Job Satisfaction: How Crucial is Participative Decision Making?", Personnel Review, 45(1): 183-200

Peter G. Northouse (2012) Leadership, Theory and Practice, Six Edition, Teller Road and Oaks, California 91320 
Pun, K.F., K.S.Chin and R.Gill 2001. Determinant of Employee Involvement Practices in Manufacturing Enterprises. Total Quality Management, Vol.12 No 1 Taylor and Frnacis Ltd. pp 95-109.

Rafferty, A.E. and Simons, R.H. (2006), "An examination of the antecedents of readiness for finetuning and corporate transformation changes", Journal of Business and Psychology, Vol. 20 No. 3, pp. 325-50.

Raymond A Noe, John H. Hollenbeck.Barry Gerhart: Patrick M.Wight (2006) Fifth Edition, McgrawHill International Book Company Inc

Ryan, J. and Tipu, S. (2013), "Leadership effects on innovation propensity: a two-factor full range leadership model", Journal of Business Research, Vol. 66 No. 10, pp. 2116-2129.

R. Wayne Mondy, 2008. Manajemen Sumber Daya Manusia jilid 1 edisi 10, Erlangga. Jakarta.

Samad, S. (2012), "The influence of innovation and transformational leadership on organizational performance", Procedia-Social and Behavioral Sciences, Vol. 57, pp. 486-493.

Schwartz, D.B., Spencer, T., Wilson, B. and Wood, K. (2011), "Transformational leadership: implications for nursing leaders in facilities seeking magnet designation", AORN Journal, Vol. 93 No. 6, pp. 737-748.

Scott, K., Bishop, J., and Chen, X. (2003). "An Examination of the Relationship of Employee Involvement with Job Satisfaction, Employee Cooperation, and Intention to Quit in US Invested Enterprise in China", The International Journal of Organizational Analysis, 11(1): 3-19.

Sekaran, Umar dan Roger Bougie. 2010. Research Methods for Business, A Skill Building Approach (Fifth Edition). Haddington : Wiley

Shah, N. (2011), "A study of the relationship between organizational justice and employee readiness for change", Journal of Enterprise Information Management, Vol. 24 No. 3, pp. 224-236.

Shiva, M. and Suar, D. (2012), "Transformational leadership, organizational culture, organizational effectiveness, and programme outcomes in non-governmental organizations", VOLUNTAS: International Journal of Voluntary and Nonprofit Organizations, Vol. 23 No. 3, pp. 684-710.

Sikh, G. (2011), "Analysis of attitudes and behaviours of employees towards organizational change", International Journal of Human Resource Management and Research, Vol. 1 No. 1, pp. 1-13.

Smith, I. (2005), "Managing the 'people' side of organisational change", Library Management, Vol. 26 No. 3, pp. 152-5.

Stephen P Robbins, Mary Coulter, (2004).Management, Eight edition

Stephen P. Robbins dan Timothy A Judge (2013). Organizational Behavior

Soltani, E. and Wilkinson, A. (2010), "Stuck in the middle with you: the effects of incongruency of senior and middle managers' orientations on TQM programmes", International Journal of Operations \& Production Management, Vol. 30 No. 4, pp. 365-397.

Sugiyono. 2008. Metode Penelitian Bisnis. Alfabeta. Bandung

Schwartz, D., Spencer, T., Wilson, B. and Wood, K. (2011), "Transformational leadership: implications for nursing leaders in facilities seeking magnet designation", AORN Journal, Vol. 93 No. 6, pp. 737-748.

Talim, B. (2012), "Creating a meaningful planned change", Procedia Economics and Finance, Vol. 4 pp. $140-148$.

Umar, Husein. 2005. Riset Sumber Daya Manusia. Jakarta: PT. Gramedia Pustaka Utama.

Van Aken, EM. and Manena, DJ. (1994). Affinity groups the missing link in employee involvement". Organizational Dinamics Spring. Vol 23, No4, pp 38-54

Van der Voet, J. (2014), "The effectiveness and specificity of change management in a public organization: transformational leadership and a bureaucratic organizational structure", European Management Journal, Vol. 32 No. 3, pp. 373-382. 
Pengaruh Kepemimpinan, Keterlibatan Karyawan dan Kepuasan Kerja terhadap Kesiapan untuk Berubah dalam Menghadapi Perubahan Organisasi

Walumbwa, F.O., Wu, C. and Orwa, B., 2008,“Contingent reward transactional leadership, work attitudes, and organizational citizenship behavior: The role of procedural justice climate perceptions and strength ", Leadership Quarterly, Vol.19 No.3, pp. 251-265.

Wanberg, C.R. and Banas, J.T. (2000), "Predictors and outcomes of openness to changes in a reorganizing workplace”, Journal of Applied Psychology, Vol. 85 No. 1, pp. 132-142.

Wang, C., Tsai, H. and Tsai, M. (2014), "Linking transformational leadership and employee creativity in the hospitality industry: the influences of creative role identity, creative self-efficacy, and job complexity", Tourism Management, Vol. 40, pp. 79-89.

Wanous, J.P., Reichers, A.E. and Austin, J.T. (2000), “Cynicism about organizational change”, Group \& Organization Management, Vol. 25 No. 2, pp. 132-53.

Ward, K. (2002), "A vision for tomorrow: transformational nursing leaders”, Nursing Outlook, Vol. 50 No. 3 , pp. $121-126$.

Weber, P.S. and Weber, J.E. (2001), "Changes in employee perceptions during organizational change”, Leadership \& Organization Development Journal, Vol. 22 No. 6, pp. 291-300.

Weeks, B., Helms, M.M. and Ettkin, L.P. (1995), "Is your organization ready for TQM? An assessment methodology", The TQM Magazine, Vol. 7 No. 5, pp. 43-49.

Weiner, B.J. (2009), “A theory of organizational readiness for change”, Implementation Science, Vol. 4 No. 67, pp. 1-9.

York J. (1995). Holistic Leadership: How to Survive and Prosper in the Coming Business Revolution, John York Publication, Australia

Zatzick, C.D., and R.D. Iverson 2011. Putting employee involvement in context: a cross-level model examining job satisfaction and absenteeism in high involement work systems, The International Journal of Human Resources Management, Vol 22.No,17, pp 3462-3476 